Research, Society and Development, v. 7, n. 7 p. 01-23, e1277348, 2018

ISSN 2525-3409 (CC BY 4.0)

\title{
Construção da identidade profissional: a motivação através da experiência como
} paciente oncológico

\section{Construction of professional identity: motivation through experience as an oncological patient}

Thaiani Selau Nunes

Universidade Federal de Ciências da Saúde de Porto Alegre, Brasil

E-mail: thaianiselau@ hotmail.com

Simone Travi Canabarro

Universidade Federal de Ciências da Saúde de Porto Alegre, Brasil

E-mail: simonetravicanabarro6@gmail.com

Gisele Pereira de Carvalho

Universidade Federal de Ciências da Saúde de Porto Alegre, Brasil

E-mail: gpcarvalho27@gmail.com

Recebido: 09/04/2018 - Aceito: 26/04/2018

\section{Resumo}

O presente estudo tem por objetivo refletir sobre como as diferentes experiências pessoais e acadêmicas contribuem com a construção da identidade profissional na enfermagem pediátrica. A presente pesquisa consiste em uma narrativa autobiográfica utilizada como instrumento para a construção de memorial formativo com abordagem qualitativa sobre o contato pessoal com a saúde como influenciador da opção acadêmica futura pela enfermagem. A experiência como paciente oncológico na infância traz à tona a discussão sobre a influência desta vivência na trajetória do sujeito, suas escolhas acadêmicas e pessoais. A forma como o paciente vivencia esta experiência e a importância deste momento na sua história apresenta-se como importante fator na opção futura pelo cuidado e como incentivador na busca de uma prática mais humanizada nas áreas de atendimento à saúde. As experiências pessoais contribuem, sobremaneira, na definição de significados para importantes aspectos que envolvem o ato de cuidar, definindo a escolha pela área da saúde e formando profissionais preparados para o desenvolvimento de um cuidado humano e empático, descortinando, ainda, a reflexão possível sobre a influência das ações dos profissionais da saúde como referências para os atendidos na construção de suas identidades e escolhas futuras.

Palavras-chave: Enfermagem Pediátrica, Humanização da Assistência; Oncologia; Enfermagem oncológica. 


\begin{abstract}
The present study aims to reflect about how different personal and academic experiences contribute to the construction of professional identity in pediatric nursing. This research consists of an autobiographical narrative used as a tool to build formative memorial with a qualitative approach about personal contact with health as influencer of future academic option for nursing. The experience as a cancer patient in childhood raises the discussion of the influence of this experience in the subject of history, his academic and personal choices. The way the patient goes through this experience and the importance of this moment in its history presents itself as an important factor in future option for the care and as a promoter in the search for a more humane practice in the areas of health care. Personal experiences contributed greatly in defining meanings for important aspects involved in the act of caring, define the choice of health care and training of qualified professionals for the development of a human caring and empathic, revealing also the possible reflection on the influence of the actions of health professionals as references for assisted in building their identities and future choices.
\end{abstract}

Keywords: Pediatric Nursing; Humanization of Assistance; Cancer Care Facilities; Oncology Nursing.

\title{
1. Introdução
}

A enfermagem, em comparação a outras profissões ligadas à saúde, é a área que atua de forma mais próxima e intensa com os sujeitos que recebem o cuidado, tornando necessário que o profissional estabeleça o atendimento ao próximo com competência e resolutividade (SILVA, et al., 2008).

Assim, espera-se que um estudante da área da saúde aprenda a se relacionar com os pacientes, preparando-se para estabelecer relações adequadas e éticas, respeitando e identificando suas reações emocionais. Segundo Eizirick et al. (2001) “isso terá decisiva importância para os diagnósticos e tratamentos das diversas situações encontradas na atividade clínica".

Se essas premissas condicionam a qualidade do atendimento de saúde, quando o paciente é uma criança com câncer essa perspectiva ganha ainda mais eloquência e causa maior impacto, levando em conta o fato de "a criança ser considerada o símbolo da vida, nascimento e esperança e o câncer, por sua vez, ainda ser encarado como a patologia da incerteza (VALLE, 1999)". 
Em estudo desenvolvido por Marques (2004) com crianças internadas em hospitais para tratamento de câncer, a maioria delas revelou sentimentos desagradáveis ligados à hospitalização, demonstrando o quanto se sentem isoladas, limitadas no brincar e impedidas de frequentar a escola.

No mesmo estudo, os pesquisados manifestaram, ainda, a esperança em terminar o tratamento o mais rápido possível, levando em conta o incômodo que o ambiente hospitalar causa como um meio de imposição do isolamento e limitação às atividades normais de uma criança. Observa-se, neste caso, que "o hospital é revestido de significados ambivalentes: por um lado representa o local que possibilita cura e/ou reabilitação, por outro tem efeito controlador, agressivo e indesejado" (MARQUES, 2004).

Diante desse contexto, as novas diretrizes curriculares para a enfermagem, preveem que o processo de formação do profissional deva estar centrado na capacidade de análise das situações e competências tanto na área administrativa quanto assistencial. As diretrizes dão ênfase, ainda, à importância da sensibilização. A empatia de compreender o contexto no qual o paciente oncológico pediátrico encontra-se como estratégia para minimizar o impacto negativo que o tratamento e o ambiente hospitalar causam na criança e nos seus familiares, torna-se fundamental para praticar, de forma efetiva, o cuidado humanizado preconizado pelos fundamentos da enfermagem.

Essas competências, no entanto, não são desenvolvidas somente com a graduação, mas decorrem, sobremaneira, de um processo de constante aprimoramento ao longo da vida pessoal e profissional (AMESTOY, 2010). Se uma criança em tratamento oncológico identifica com clareza as limitações que o processo impõe, pode, por outro lado, encontrar equivalências que amenizam o tratamento e que podem servir de estímulo momentâneo e futuro.

Somos resultados de influências contínuas das nossas relações interpessoais e dos meios com os quais interagimos, e estas influências podem condicionar nossas formas de pensar, agir, e determinar caminhos a percorrer e escolhas futuras a fazer.

Assim, o presente trabalho dedica-se a tecer a relação entre a experiência pessoal como paciente oncológico pediátrico e a opção pela enfermagem. De caráter narrativo autobiográfico, o trabalho desenvolverá um memorial formativo com abordagem qualitativa sobre a influência do contato pessoal com a saúde na escolha acadêmica pela enfermagem.

Ao determinar o caminho a ser percorrido, identificamos a escassa produção científica sobre a influência que o adoecimento na infância exerce sobre a escolha profissional no futuro, o que serviu de motivação para a reflexão e de incentivo para relatar a minha trajetória 
pessoal até a opção pela enfermagem. Dessa forma, questionamentos surgiram para instrumentalizar o percurso: De que maneira a experiência como paciente oncológico pode contribuir para a escolha da enfermagem? O processo de tratamento hospitalar na infância pode influenciar na construção da identidade profissional na saúde?

Assim, a presente pesquisa objetiva identificar possíveis respostas aos problemas centrais e às demais questões que emergiram ao longo do caminho, em caráter provisório e inconcluso, de modo que possa fomentar novos percursos acadêmicos de pesquisa ao tema. A importância deste estudo, portanto, é apontar os elementos que contribuem para uma formação na área da saúde voltada à humanização da assistência, valorizando as experiências pessoais no processo de aprendizagem, com a possibilidade de aprimoramento permanente desses significados para uma prática inspiradora e de excelência.

Este memorial formativo apresenta reflexões sobre a minha experiência em tratamento oncológico na infância e a contribuição deste acontecimento na escolha profissional pela enfermagem, e de modo especial pelo cuidado ao paciente pediátrico. Assim, o estudo tem por objetivo refletir sobre como as diferentes experiências pessoais e acadêmicas podem contribuir para a construção da identidade profissional na enfermagem pediátrica.

\section{Metodologia}

O presente estudo caracteriza-se como uma pesquisa qualitativa do tipo autobiográfica, que utiliza a narrativa para a construção de um memorial formativo, propondo reflexões a partir da interlocução de percepções pessoais e produções acadêmicas.

Para Denzin e Lincoln (2006) a pesquisa qualitativa busca a relação entre os valores e a natureza para sua investigação, no modo como a experiência social é criada, e a forma como o seu significado é adquirido. Minayo (2010), por sua vez, afirma que a pesquisa autobiográfica é considerada um poderoso instrumento para explorar e descobrir a forma como as pessoas compreendem seu passado, vinculando suas experiências individuais no contexto social, avaliando e interpretando os significados subjetivos dos acontecimentos.

As narrativas são utilizadas para abordar a história do objeto investigado. Como afirma Polit e Beck (2011), ao adotar a narrativa, avaliamos o sentido dos eventos em suas experiências, descrevendo a importância deste para os outros e comunicando seus significados implícitos entre motivações e ações, compreendendo o processo de socialização nas relações pessoais.

Para Leitão e Vieira (2012), 
Research, Society and Development, v. 7, n. 7 p. 01-23, e1277348, 2018

ISSN 2525-3409 (CC BY 4.0)

um memorial consiste em resgatar as lembranças significativas dos processos de aprendizagem, buscando encontrar os elementos constituintes na trajetória de formação que compreendem os acontecimentos essenciais ligados ao cuidado na experiência de formação não só acadêmica e profissional, mas também de toda a vida pessoal.

Optou-se, portanto, pela utilização dessa metodologia para descrever as experiências que contribuíram no desenvolvimento do (meu) perfil pessoal, com reflexo direto na identidade e nas escolhas profissionais voltadas à correta prática do cuidado humanizado na saúde.

Em respeito aos preceitos éticos, este trabalho segue a Resolução n ${ }^{\circ}$ 9.610/98 da Legislação sobre Direitos Autorais (BRASIL, 1998), no qual são citados os autores utilizados no memorial de formação. Por tratar-se de uma narrativa, cabe esclarecer que se optou por omitir nomes de pessoas, lugares e instituições no sentido de respeitar e preservar o anonimato destes. Dessa forma, as reflexões são de responsabilidade exclusiva do autor, no que tange à descrição das memórias narradas.

\section{Memorial de Formação}

Todas as experiências vividas nos vínculos humanos e a interação com o ambiente moldam a personalidade que desenvolvemos durante todo nosso ciclo vital (EIZIRICK et al., 2001).

As experiências descritas a seguir constituem parte das minhas memórias pessoais, portanto, eu, pesquisadora, assumo a pessoa da narrativa e compartilho aqui as vivências do meu tratamento oncológico na infância e na adolescência.

Há alguns anos, precisamente em 2003, aos 8 anos de idade, vivenciei uma reviravolta na minha infância. Inicialmente apresentei aumento nas tonsilas, tratada inúmeras vezes como mononucleose infecciosa. Com o passar das semanas passei a apresentar aumento nos linfonodos na região cervical, que de acordo com os médicos, ocorria por conta da infecção.

No início de julho de 2003, durante o banho, notei uma ondulação anormal na virilha. Compartilhei o incômodo com meus pais, ao que eles, imediatamente voltaram a consultar o médico. Ainda sem determinar o meu diagnóstico real, o médico pediu que eu realizasse um controle por meio de ecografias. Ao realizar os exames, o laudo apontou nódulos na coxa 
direita medindo $5,9 \mathrm{~cm}$ x 4,5 $\mathrm{cm}$ x 2,4 cm, com volume aproximado de $33,1 \mathrm{~cm}^{3}$. Na coxa esquerda apresentava uma imagem com as mesmas características, medindo, porém, $4,4 \mathrm{~cm} \mathrm{x}$ $2,4 \mathrm{~cm} \mathrm{x} \mathrm{1,8} \mathrm{cm,} \mathrm{com} \mathrm{volume} \mathrm{total} \mathrm{de} 9,8 \mathrm{~cm}^{3}$. As descobertas correspondiam a linfonodos inguinais.

Com o passar do tempo, percebia que o tamanho dos nódulos aumentava gradativamente ao passo que novas formações surgiram na região axilar. Nesse momento, portanto, tornou-se necessária a realização de uma biópsia. Assim, no dia 4 de agosto de 2003, o procedimento foi realizado no nódulo da região inguinal direita, que apresentou uma proliferação linfóide atípica composta por linfócitos varialmente clivados, de tamanho médio e alto índice mitótico, compatível com Linfoma Não-Hodgkiniano Linfoblástico de células precursoras (CID 83.5). Assim, estava determinado o diagnóstico, tratava-se de câncer.

Embora considerado raro na infância, segundo Pedrosa (2007), o linfoma em crianças e adolescentes vem recebendo cada vez mais atenção entre os pesquisadores, "não só por sua importância crescente do ponto de vista epidemiológico, como também pelos grandes avanços observados no seu diagnóstico e tratamento".

O câncer infantil corresponde a um grupo de várias doenças que têm em comum a proliferação descontrolada de células anormais e que pode ocorrer em qualquer local do organismo. Os tumores mais frequentes na infância e na adolescência são as leucemias (que afeta os glóbulos brancos), os do sistema nervoso central e linfomas (sistema linfático) (INCA, 2018).

Estima-se que ocorrerão cerca de 12.500 casos novos de câncer em crianças e adolescentes no Brasil por ano em 2018. As regiões Sudeste e Nordeste apresentarão os maiores números de casos novos, seguidas pelas regiões Sul, Centro-Oeste, e Norte (INCA 2018).

Nesse contexto, os linfomas representam a terceira neoplasia maligna mais frequentemente diagnosticada em crianças e adolescentes na faixa etária de 0 a 15 anos, sendo $60 \%$ dos casos representados pelos linfomas não-Hodgkin (LNH) e $40 \%$ pelos linfomas de Hodgkin (PEDROSA, 2007).

Os linfomas de alto grau são responsáveis por cerca de $50 \%$ de todos os casos de LNH e engloba o linfoma não-Hodgkin difuso de grandes células B, o linfoma folicular pouco diferenciado, o linfoma de células do manto, o linfoma de células T periférico e o linfoma de grandes células anaplásico (ARAÚJO, 2008).

Nas últimas quatro décadas, o progresso no tratamento do câncer na infância e na adolescência foi extremamente significativo. Hoje, em torno de $80 \%$ das crianças e 
adolescentes acometidos de câncer podem ser curados, se diagnosticados precocemente e tratados em centros especializados. A maioria deles terá boa qualidade de vida após o tratamento adequado (INCA, 2018).

Após o diagnóstico, tornou-se necessário o início imediato do tratamento a fim de minimizar complicações futuras. Fui, então, direcionada à instituição de tratamentos neoplásicos na infância, onde realizei repetidas baterias de exames além de iniciar o processo de quimioterapia. Este local, de forma particular, me acolheu e proporcionou reflexões sobre a vida, a saúde, a família e, principalmente, foi determinante no processo que me ensinou o significado de fé.

Nessa direção, o cuidado espiritual deve ser entendido como parte do cuidado global de enfermagem à família e não apenas como um fragmento isolado. “É necessário planejar o cuidado com o paciente considerando a espiritualidade, ressaltando que este se trata de um aspecto individual, que depende da experiência de vida de cada membro da família" (WILFRED, 2006). O cuidado espiritual é um desafio para o enfermeiro. Paula (2009) complementa que o papel do profissional "no cuidado espiritual da família, implica em estar presente, ouvir sobre as necessidades dos familiares e respeitar suas crenças e valores".

Este foi, para minha família, um momento de muita angústia, dor e mesmo desespero. Tal fato nunca é esperado no seio familiar a ocorrer em entes queridos. Minha situação de saúde, porém, fez com que os membros da minha família se unissem, trabalhando em conjunto para me proporcionar carinho e atenção neste difícil e doloroso momento.

Como afirma Barreto e Amorim (2010), o processo oncológico desencadeia sofrimento não apenas ao paciente, mas pode envolver familiares provocando fragilidade emocional e física. Em algumas situações, no entanto, conforme sinalizam os autores, os familiares unem-se a fim de contribuir com as estratégias de enfrentamento da doença e das consequências provocadas pelo tratamento.

Para Elsen (2004):

A presença dos familiares, geralmente, promove e mantém a interrelação criança/família, neutraliza os efeitos decorrentes da separação de seus membros, colabora na assistência integral à criança, melhora sua adaptação ao hospital, facilita a aceitação do tratamento, promove positiva resposta terapêutica e ameniza os fatores estressantes da doença, dos procedimentos e da hospitalização. 
Não guardo muitas lembranças da forma como tudo ocorreu, sei, no entanto, que foi difícil me afastar da escola, não ver meus colegas, enfrentar dias e noites de quimioterapia em um lugar estranho, sendo exposta a dezenas de procedimentos invasivos. Minha saúde, que antes da descoberta da doença me obrigava a realizar apenas exames de sangue e de rotina, de repente impôs novos desafios em uma realidade hospitalar nova e assustadora.

A possibilidade de cura ou controle da doença fornecida pela quimioterapia usualmente está ligada a uma série de efeitos colaterais incômodos que exigem, tanto das crianças quanto de seus cuidadores, o uso de modos para lidar com os problemas, a fim de facilitar o enfrentamento das vicissitudes do adoecimento e tratamento (ALMICO, 2014).

Segundo Dalmolin et al. (2011) o contexto de vida de cada indivíduo determina as características do significado atribuído ao processo de viver e adoecer. Para o autor, "mesmo em condições de doença é possível viver saudável, envolvendo a saúde num modo de ser e produzir, ou até mesmo recriar a vida a partir de uma condição singular e multidimensional" (DALMOLIN, 2011).

Barreto e Amorim (2010) definem o câncer como "uma doença crônica, não transmissível, caracterizada pela proliferação descontrolada de células anormais do organismo que, geralmente formam um tumor", e o tratamento como possibilidade de cura ou de prolongar a vida, assume diversas modalidades terapêuticas: a quimioterapia, radioterapia, imunoterapia, hormonioterapia ou cirurgia. Algumas terapias, como as medicações utilizadas na quimioterapia, não possuem o caráter seletivo ao interferir no processo de divisão celular, agindo também em células sadias como as células do folículo piloso, germinativo e do aparelho gastrointestinal, trazendo impacto também relacionado ao tratamento.

Assim, embora sem a completa compreensão do contexto no qual me vi inserida de forma imprevisível e imediata, assimilei as informações necessárias para entender o grau de complexidade da minha doença e, nesse sentido, o contexto contribuiu, sobremaneira, para o meu amadurecimento durante o tratamento e a internação.

Essa maturidade psicológica e social foi fator determinante para a minha opção por viver e para que eu pudesse ver, na saúde, representada pela figura dos profissionais que acompanhavam o meu tratamento, a cura, a vida e a esperança. Essas percepções, no entanto, só foram possíveis graças ao preparo da equipe de profissionais responsáveis pelo meu tratamento.

A representação de doença como algo que é para além do diagnóstico centrado no corpo biológico representa, também, as transformações que o sujeito está vulnerável ao meio, seja na forma física, psicológica, social ou espiritual (WALDOW; BORGES, 2008). Há uma 
linha tênue entre a vida e a morte nos diagnósticos de câncer. Segundo Barreto e Amorim (2010),

essa relação geralmente pode estar associada a perdas, morte e alteração da imagem corporal, desencadeando sentimentos e consequências biopsicossociais para a pessoa doente e ao sistema familiar, sendo imprescindível à equipe de enfermagem planejar ações adequadas orientando os pacientes conforme suas necessidades.

Ainda que fosse um processo triste e mesmo doloroso, conseguia compreender a importância da realização dos procedimentos médicos e de enfermagem. A partir da compreensão madura do tratamento e de todos os reflexos do trabalho incansável das equipes que cuidavam de mim, pude observar a importância da enfermagem no tratamento e nos resultados com ele alcançados rumo à minha melhora.

$\mathrm{O}$ apoio que recebi desses profissionais tornou o período em que estive debilitada e internada para o tratamento o menos traumático possível. O cuidado humanizado prestado pelos profissionais, assim como o trabalho qualificado da equipe multidisciplinar comprometida em proporcionar um ambiente terapêutico, com recreação, auxílio pedagógico e acompanhamento psicológico foram fatores determinantes para minimizar os impactos provocados pelas condições impostas pela doença.

Autores mostram na literatura a necessidade de criar um ambiente propício ao brincar no hospital, reforçando a importância que a atividade lúdica traz não apenas para a criança, mas também para todo o hospital, melhorando a saúde física, emocional e social dos indivíduos. Vale ressaltar ainda que, no processo de humanização hospitalar infantil, deve-se privilegiar a brincadeira. É imprescindível que esse processo se estenda à estrutura física do hospital e aos profissionais, de modo que o paciente possa participar ativamente do tratamento, pois, por meio da brincadeira, os problemas comportamentais e emocionais dessa população são amenizados, favorecendo a internação tornando este momento transitório menos assustador (HOSTERT, 2014).

De acordo com Waldon e Borges (2011), para praticar a ação de cuidar é necessário “estabelecer um laço de confiança com aqueles que recebem o cuidado, seja paciente ou 
familiar, demonstrando responsabilidade, competência, respeito e sensibilidade, integrando o ser seja qual for o resultado de sua condição (...)".

Em agosto de 2003 fui internada para realizar uma extensa lista de exames e o procedimento de colocação do Dispositivo Venoso Central Totalmente Implantado Portocath, para iniciar as quimioterapias. Nesse momento lembro-me de sentir angústia e preocupação com as incertezas sobre a evolução do tratamento.

$\mathrm{Eu}$ e meus pais, no entanto, recebemos as explicações necessárias sobre todo o procedimento, fazendo com que uma parcela da angústia cedesse e desse lugar ao otimismo e à esperança. Segundo Oliveira (2011), a adaptação do cuidado moldado nas expectativas e valores do paciente e de sua família "reflete na aceitabilidade do tratamento, integrando o saber científico com o contexto pessoal, na busca da satisfação dessa interação".

Resgatando na memória a trajetória do tratamento, posso recordar que a explicação tranquilizadora e esclarecedora veio de um profissional que utilizava roupa branca, - havia, ainda, os que utilizavam roupa azul e os que usavam jaleco - certificando que tratava-se de um enfermeiro, o profissional responsável pela maior parte da educação em saúde nos ambientes de cuidado, tanto na atenção básica como em ambiente hospitalar.

Esse processo aproxima a enfermagem do paciente, fazendo com que ele se sinta seguro por meio das explicações realizadas que traduzem a linguagem da saúde para a compreensão dele e dos familiares. Faria e Santos (2011) dão legitimidade a esse processo quando reforçam “a importância da comunicação entre profissional e paciente para uma relação verdadeiramente terapêutica dando qualidade à assistência".

Como citado por Ferraz (2005) a utilização da educação como forma de cuidar na enfermagem transcende os preceitos básicos do cuidado, pois,

por meio do educar o enfermeiro potencializa a capacidade de cuidar, e a utilização desta os capacita a intervir de forma construtiva nas relações desenvolvidas entre os sujeitos, onde um aprende com o outro. No cuidado à criança sempre se encontra espaços para a educação em saúde. O processo educativo deve permear todas as práticas do cuidado infantil e envolver seus familiares nesse processo.

A prática da educação em saúde me fez perceber que essas ações aproximam o enfermeiro ao paciente, estabelecendo uma relação de confiança, sobretudo com a criança, pois, diversas vezes, os procedimentos são explicados somente aos pais, sem esclarecer, pedir 
o consentimento e conversar com ela. Por meio dessas ações e da relação de confiança que estabeleci com a equipe de enfermagem, os momentos de internação tornaram-se menos desagradáveis e o vínculo construído com os profissionais serviu para reduzir o medo de estar no ambiente hospitalar e minimizar as angústias e incertezas do tratamento.

Em 17 de agosto de 2003, internei para o início da quimioterapia de indução do protocolo Children's Oncology Group trial A5971 (CCG 5971), que contempla drogas como a Vincristina, Daunorrubicina, Prednisona, Asparaginase, Ciclofosfamida, Citarabina, Metotrexato e Mercaptopurina. O protocolo dividiu-se em fase de indução, consolidação, manutenção precoce, manutenção tardia e manutenção a longo prazo.Ao final da fase de indução, pouco mais de um mês após o início do tratamento, tive um quadro de intercorrência, sendo necessário buscar atendimento médico de urgência ao apresentar um quadro de hematúria e cólica nefrética. Nos resultados dos exames, a equipe constatou a presença de cálculos. Lembro-me da dificuldade enfrentada neste momento por conta do grau elevado de dor, dez na escala médica, como ainda não havia sentido durante o tratamento.

Foi, então, necessária a realização da sondagem vesical de alívio para diminuir o desconforto e a dor. As lembranças que se acumulam na medida em que percorro o caminho da lembrança para reconstruir a história, trazem à tona o olhar de minha mãe, angustiada e nervosa, chorando ao testemunhar mais este sofrimento. Segundo Ortiz (2003), a mãe da criança com câncer também está psiquicamente vulnerável às experiências decorrentes da doença, já que é ela a principal interlocutora e cuidadora nesta situação.

Esta vulnerabilidade psíquica diz respeito a todas as angústias resultantes de todo o processo que envolve a doença, desde o diagnóstico até o fim do tratamento, além das crises familiares que ocorrem como consequência de uma redefinição do papel da mãe dentro da família.

O diagnóstico, por fim, apontou cálculo no ureter, medindo $0,7 \mathrm{~cm}$, retirado por cistoscopia, seguido da colocação de cateter duplo J. Após três dias do procedimento, recebi alta hospitalar para seguimento no ambulatório de quimioterapia e prosseguimento à nova fase, de consolidação.

Cardoso (2007), cita que são diversos os efeitos colaterais provocados pelo tratamento do câncer, tais como: náuseas, vômitos, queda de cabelo, úlceras bucais, ganho de peso, amputação, esterilidade, danos cerebrais e atraso no crescimento. Com o seguimento do protocolo, não sofri muitos dos efeitos colaterais citados pelo autor, exceto náusea, vômitos e perda de apetite, alopecia e o aspecto cushingóide, causado pelo uso contínuo de corticóides que me acompanharam por todas as fases do tratamento. 
Durante todo o processo, tive as atividades escolares suspensas, reduzindo significativamente o vínculo escolar e a vivência com a rotina de aprendizagem da sala de aula. Perdi a convivência com colegas de aula e estava limitada a brincadeiras dentro de casa. Vieira (2001) analisa como a internação impacta no processo de aprendizagem da criança, ao afirmar que:

no caso das crianças com câncer, a permanência em período longo de tratamento no hospital as impossibilita de frequentarem a instituição educativa, deixando de desenvolver algumas de suas capacidades cognitivas e começando a apresentar algumas dificuldades de aprendizagem [VIEIRA, 2001].

Para não perder a continuidade dos estudos contei com o apoio escolar de uma pedagoga vinculada ao hospital, que recebia as tarefas escolares enviadas pelo colégio e me ensinava durante a internação, diminuindo o prejuízo aos estudos.

Vieira sinaliza, ainda, que o desenvolvimento de práticas pedagógicas com crianças enfermas é um grande avanço, visto que "a partir da relação entre família, equipe de saúde e equipe educacional, propicia-se a continuidade de um projeto de vida, o desenvolvimento do conhecimento infantil e a realização pessoal das crianças" (VIEIRA, 2001).

A partir da observância destas peculiaridades inerentes ao processo educativo de crianças hospitalizadas para tratamento o Conselho Nacional dos Direitos da Criança e do Adolescente reconheceu, por meio da Resolução no 41/1995, o direito destes de desfrutar de alguma forma de recreação, programa de educação para saúde e acompanhamento do currículo escolar durante a permanência hospitalar.

Por fim, Viera observa que, embora reconhecida a importância da prática docente em ambiente hospitalar como fonte primária de acesso ao conhecimento das crianças hospitalizadas, a formação profissional na educação ainda carece desta abordagem e do preparo necessário ao professor para atuar junto às crianças hospitalizadas, pois este universo é "pouco explorado como lócus próprio de atuação do professor e de pesquisa para a construção de novas práticas pedagógicas" (VIEIRA, 2001).

Ao entrar na fase de manutenção, com duração de um ano, comecei a frequentar a escola com algumas restrições. Nesta etapa do tratamento, comecei a experimentar maior liberdade, com redução significativa nas internações e com acompanhamento mediante 
consultas ambulatoriais semanais. No dia 8 de agosto de 2005, após a realização de exames, o tratamento, finalmente, chegou ao fim.

O acompanhamento tornou-se mensal, para avaliações periódicas, e estendeu-se assim durante 10 anos. À medida que o tempo foi passando, as consultas tornaram-se menos frequentes e mais descontraídas, o que fazia com que me sentisse melhor e mais saudável. Aos poucos pude voltar às atividades escolares sem nenhuma restrição, retornando, gradativamente, à rotina e à convivência de amigos e colegas.

No final do ano de 2015, 10 anos depois do fim do tratamento e do início do acompanhamento periódico, recebi alta dos cuidados da equipe de oncologia pediátrica, me desvinculando da instituição de saúde que me acolheu por tantos anos. A maturidade adquirida ao longo do processo foi, aos poucos, mostrando-me a importância dos momentos vivenciados na trajetória, da atuação qualificada da equipe de profissionais de saúde envolvidos no meu tratamento e da complexidade que envolve a profissão ligada à saúde como esteio nos momentos desafiadores e esperança no caminho rumo à cura e à opção pela vida.

Depois de vivenciar a experiência hospitalar, conviver dia a dia com a rotina da internação e observar a prática do cuidado na enfermagem, a opção pela profissão como caminho futuro descortinou-se naturalmente na trajetória e determinou minhas escolhas acadêmicas e profissionais.

Ao final do ensino médio, os jovens enfrentam o momento crucial de transição marcado pelo fim da rotina escolar, pelos desafios do ingresso na vida acadêmica, e pelas escolhas importantes que condicionam o futuro. A enfermagem já estava no meu íntimo e não houve dúvidas quanto à opção pela saúde, pelo cuidado com os pacientes, pela multidisciplinariedade, pelo vínculo com o paciente e pela importância do profissional no cuidar.

O ingresso na Universidade descortina inúmeras opções de trajetórias acadêmicas e profissionais, apresentando ênfases e áreas nas quais os estudantes possuam maior afinidade e possam se especializar. Já nas primeiras práticas assistidas, pude identificar minha afinidade pela área de pediatria.

Durante os anos de graduação que se seguiram, busquei aperfeiçoamento no cuidado da criança e do adolescente, buscando a excelência e a oportunidade de empregar minhas experiências pessoais como amplificadores do conhecimento científico, com vistas a oferecer um cuidado mais humanizado e empático. 
Research, Society and Development, v. 7, n. 7 p. 01-23, e1277348, 2018

ISSN 2525-3409 (CC BY 4.0)

Com a realização das práticas nos diversos eixos do cuidado de enfermagem, percebi o quanto a experiência pessoal anterior me aproximou dos processos de adoecimento e de procedimentos invasivos com naturalidade e familiaridade, o que se tornou um diferencial significativo em comparação a outros colegas que estabeleciam os primeiros contatos com esta área do saber e evidenciavam incômodo e perplexidade diante de procedimentos específicos. Esta experiência contribuiu, ainda, na partilha com os colegas, oportunidades de relatar vivências pessoais e exemplificar pontualmente situações cotidianas experimentadas na prática.

Como afirma Fão (2012),

não só o que aprendemos nas aulas teóricas ao longo da graduação do curso de enfermagem, mas também as experiências que temos durante esse processo, seja nos estágios curriculares ou extracurriculares, servem para aprimorarmos nossas habilidades para lidar com as pessoas ao longo da nossa vida pessoal e profissional.

Juntamente ao término do meu acompanhamento na oncologia pediátrica, vivenciei uma das melhores experiências acadêmicas extracurriculares. Pude encerrar ciclos pessoais e iniciar novas vivências acadêmicas e profissionais. Ao participar de um processo seletivo para a realização do curso de férias de capacitação em saúde da criança e da família, retornei à instituição onde realizei meu tratamento e que me acolheu durante tantos anos.

A mudança do papel de paciente para provedor de cuidado me permitiu refletir sobre o processo de doença e incentivar as crianças internadas a lutarem e alimentarem a esperança pela cura, muitas vezes quase extinta e desacreditada pelos pacientes e por seus acompanhantes.

Em um primeiro momento, pensei que seria este um grande desafio emocional capaz de gerar desestabilização levando em conta o resgate de um processo já superado e que a consequência desta retomada pudesse interferir na continuidade de minhas atividades acadêmicas. O que ocorreu, porém, foi, definitivamente, contrário a todas as angústias que precederam essa experiência.

Pude compartilhar minha história com as famílias e com os pacientes, que se emocionavam com a partilha das experiências vivenciadas durante meu tratamento e recarregavam suas esperanças, muitas vezes extintas ou enfraquecidas pelo dia-dia exaustivo da doença. 
Nessa direção, Alecrim e Campos (2009) indicam os diferenciais para liderança na enfermagem ao afirmarem que "incentivar e estimular a equipe a desenvolver o diálogo com os pacientes, e também trabalhar com estes a relevância do seu trabalho, (...) são estratégias que motivam, sendo fundamentais para a liderança em enfermagem".

Se, por um lado esse estágio extracurricular, me proporcionou experiências positivas e revigorantes que assentiam a minha escolha pela enfermagem, por outro, a experiência de perder um paciente trouxe à tona a realidade velada do cuidado e do triste desfecho de muitas famílias, presente permanentemente no dia-dia dos profissionais da saúde. Como afirmam Toledo e Priolli (2012),

torna-se necessário reforçar nos currículos dos cursos da área da saúde mais reflexões que desenvolvam no aluno estratégias e motivação para enfrentar positivamente o processo de morrer, repensar no sistema de apoio aos familiares, encorajar estes no processo de luto, e não tentar minimizá-lo ou evitá-lo completamente.

A morte do paciente oncológico e, principalmente, na esfera pediátrica, gera uma grande sobrecarga emocional, visto que a perda de uma criança amplifica a dor pelos momentos ainda não vividos e ecoa no sofrimento dos familiares decorrente da perda de um ente querido e tão desejado pelos pais que, nestas circunstâncias comprometem emprego, e mesmo o convívio com outros filhos e familiares para estarem presentes na internação daquele que se encontra debilitado.

Nessa direção, Cantídio et al. (2011) dissertam sobre os significados da morte e do morrer. Segundo os autores, para alunos de enfermagem, ao passo que a morte causa curiosidade sobre seus aspectos desconhecidos e misteriosos, também é motivo de frustrações e tristezas em relação à sensação de perda atribuída ao ser, pois "o aluno pode encontrar-se pensando na ineficiência de suas intervenções como cuidador, e passa a considerar o fracasso no processo de cuidar, pondo em vista sua capacidade de cuidar, se sentido impotente diante da morte" (CANTÍDIO et al., 2011).

Fão (2012) acrescenta que, além da exaustão psicológica do processo e do impacto emocional causado pela perda, as questões burocráticas que sucedem o óbito também são necessárias no enfrentamento da situação. Assim, o impacto provocado pela necessidade de lidar com as perdas interferiu na minha formação profissional, servindo, sobremaneira, para amadurecer as relações no ambiente hospitalar e o contato inevitável e constante com a morte, 
ainda que essas premissas não tenham sido abordadas de forma aprofundada e enfática no âmbito acadêmico.

A esse respeito, Françoso (1996) afirma:

A ênfase na cura, apregoada durante a formação acadêmica dos profissionais de saúde, considerada, muitas vezes, como finalidade única e associada à crença na onipotência da tecnologia de última geração dificultam o enfrentamento das situações vividas cotidianamente, pelo enfermeiro, nas instituições assistenciais. Essas dificuldades profissionais vão além da não aceitação, pois manifestam-se na pouca ou nenhuma habilidade em manejar de forma adequada a ocorrência, sobretudo quando envolve a vida de uma criança.

As reflexões acerca do processo de enfrentamento da morte e da busca incessante pela cura tanto na minha trajetória pessoal quanto nas experiências acadêmicas serviram para o processo recursivo de idas e vindas da construção da identidade profissional na enfermagem.

Agrupar os elementos motivadores da caminhada em busca da legitimação dessa identidade foi fator fundamental para reconhecer a importância dos cuidados de enfermagem associados ao compromisso com o paciente, à postura empática e humanística e ao conhecimento técnico científico a fim de proporcionar assistência qualificada e eficiente.

\section{Conclusão}

A experiência como paciente oncológico na infância trouxe à tona a discussão da influência desse período na jornada acadêmica e pessoal do profissional de enfermagem. A importância desse momento apresenta-se como possibilidade crucial na escolha pelo cuidar e incentivo à procura constante de uma prática mais humanizada.

Ao ingressar em uma Universidade, independentemente do curso de graduação, o acadêmico traz consigo uma bagagem emocional e pessoal tão importante para o desempenho de suas funções quanto o aprendizado técnico e científico construído na graduação no processo de construção da identidade profissional.

As experiências acadêmicas com o cuidado me fizeram perceber o quanto as vivências pessoais contribuíram na construção da identidade profissional na enfermagem pediátrica. Os 
reflexos desse processo evidenciam a busca permanente de um cuidado humanizado e empático, focado na valorização do apoio ao paciente e à sua família e suas necessidades, levando em consideração as peculiaridades no cuidado do paciente oncológico.

As estratégias de apoio durante o meu tratamento assumiram importância fundamental para o enfrentamento da doença e aplicaram significado diferenciado ao conhecimento adquirido durante a graduação, de modo a agregar positivamente saberes e experiências e afastando qualquer resquício de trauma emocional.

Ser portadora dessa bagagem pessoal me faz valorizar o trabalho da enfermagem na figura do trabalho das equipes multidisciplinares e do apoio necessário à criança e à família nos momentos de fragilidade e sensibilização vivenciados ao longo do tratamento.

A escassez de literatura especializada propondo discussões sobre a influência do adoecimento na infância na escolha profissional futura, serviu como motivação para impulsionar a reflexão e como incentivo para relatar minha história em um movimento permanente de construção da memória pessoal e legitimação através de recortes acadêmicos, almejando, portanto, tornar-se, ou não, um trabalho precursor de outros estudos que abordem a perspectiva da escolha profissional pela área da saúde de crianças que passaram por processo de adoecimento.

Uma análise inconclusa e provisória da produção acadêmica sugere a hipótese de que essas escolhas estão diretamente relacionadas a uma boa qualidade na assistência, formando, assim, adultos que valorizam os profissionais envolvidos no processo de cuidado, e podendo, ainda, gerar motivação para o futuro profissional.

Através disso, é proposto a utilização dessas experiências para permear e indagar novas pesquisas sobre as experiências dos pacientes oncológicos, indagando novos estudos sobre a qualidade de vida a longo prazo e como essas experiências hospitalares repercutem na vida profissional e acadêmica.

A escolha pela enfermagem se reafirmou no momento em que estive na posição de cuidador e não mais de paciente e possibilitou refletir sobre a forma de prestação do cuidado e de gerenciamento da equipe, com vistas à prestação de assistência de qualidade, tal como recebi. As boas lembranças de práticas humanizadas e do cuidado de qualidade recebido foram fundamentais na minha escolha pela enfermagem, refletindo a importância de bons exemplos e de uma atuação voltada à excelência na assistência à criança adoecida com um olhar para o cuidado integral, carregado de saberes e fortalecido pelas experiências. 


\section{Referências}

ALECRIM, Joseane Santos; CAMPOS, Luciana de Freitas. Visão dos técnicos e auxiliares de enfermagem sobre o estilo de liderança do enfermeiro. Cogitare Enferm., Paraná, v.14, n.4, p.628-37, out/dez, 2009.

ALMICO, Thatianne; FARO, André. Enfrentamento de cuidadores de crianças com câncer em processo de quimioterapia. Psicologia, saúde \& doenças, v. 15, n. 3, p. 723-737, 2014.

AMESTOY, Simone Coelho et al. Processo de formação de enfermeiros líderes. Rev. Bras. Enfermagem, Brasília, v.63, n.6, p.940-5, nov/dez, 2010.

ARAÚJO, Luiz Henrique de Lima et al. Linfoma não-Hodgkin de alto grau-Revisão da literatura. Revista brasileira de cancerologia, Brasília, v. 54, n. 2, p. 175-183, 2008.

ARAÚJO, Monica Martins Trovo; SILVA, Maria Júlia Paes. Estratégias de comunicação utilizadas por profissionais de saúde na atenção à pacientes sob cuidados paliativos. Rev. Esc. Enferm. USP, São Paulo, v.46, n.3, p.626-32, 2012.

BAGGIO, Maria Aparecida; ERDMANN, Alacoque Lorenzini. Relações múltiplas do cuidado de enfermagem: o emergir do cuidado "do nós”. Rev. Latino-Am. Enfermagem [online], v.18, n.5, 8p., set/out, 2010.

BARRETO, Thâmara Sena; AMORIM, Rita da Cruz. A família frente ao adoecer e ao tratamento de um familiar com câncer. Rev. Enfermagem UERJ, Rio de Janeiro, v.18, n.3, p.462-7, jul/set, 2010.

BARROS, Maria Elizabeth; GOMES, Rafael da Silveira. Humanização do cuidado em saúde: de tecnicismos a uma ética do cuidado. Fractal: Revista de Psicologia, Rio de Janeiro, v.23, n.3, p.641-58, set/dez, 2011.

BOFANDA, Diego et al. A integralidade da atenção à saúde como eixo da organização tecnológica nos serviços. Ciência e Saúde Coletiva, Rio de Janeiro, v.17, n.2, p.555-60, 2012. 
CÂMARA, Ana Maria Chagas Sette et al. Percepção do processo saúde-doença: significados e valores da educação em saúde. Rev. Brasileira de Educação Médica, Brasília, v.36, supl.1, p.40-50, 2012.

CANTÍDIO, Farley Soares; VIEIRA, Maria Aparecida; SENA, Roseni Rosângela.

Significado da morte e de morrer para os alunos de enfermagem. Invest. Educ. Enfermagem [online], v.29, n.3, p.407-18, 2011.

CARDOSO, Flávia Tanes. Câncer infantil: aspectos emocionais e atuação do psicólogo. Rev. SBPH, Rio de Janeiro, v. 10, n. 1, p. 25-52, jun. 2007.

ORGANIZAÇÃO MUNDIAL DA SAÚDE. CID-0: classificação internacional de doenças para oncologia. 2. ed., São Paulo: Fundo Editorial Byk, 1996. 112 p.

COMBINATO, Denise Stefanoni; QUEIROZ, Marcos de Souza. Um estudo sobre a morte: uma análise a partir do método explicativo Vigotski. Ciência e Saúde Coletiva, Rio de Janeiro, v.16, n.9, p.3893-900, 2011.

DALMOLIN, Bárbara Brezolin et al. Significados do conceito de saúde na perspectiva de docentes da área da saúde. Esc. Anna Nery, Rio de Janeiro, v.15, n.2, p.389-94, abr/jun, 2011 .

DE MEDEIROS, Eduarda Gayoso Meira Suassuna et al. Repercussões do câncer infantil no cotidiano do familiar cuidador. Northeast Network Nursing Journal, v. 15, n. 2, 2014.

DOULAVINCE AMADOR, Daniela et al. Repercussões do câncer infantil para o cuidador familiar: revisão integrativa. Revista Brasileira de Enfermagem, v. 66, n. 2, 2013.

DENZIN, Norman K.; LINCOLN, Yvonna S. O Planejamento da Pesquisa

EIZIRICK, Cláudio; KAPCZINSKI, Flávio; BASSOLS, Ana. Noções Básicas sobre o funcionamento psíquico. IN: (orgs.). $\mathbf{O}$ ciclo da vida humana: uma perspectiva psicodinâmica. Porto Alegre, Artmed, 2001, p.15-27. 
Research, Society and Development, v. 7, n. 7 p. 01-23, e1277348, 2018

ISSN 2525-3409 (CC BY 4.0)

ELSEN, Ingrid; MARCON, Sonia Silvia; SILVA, Mara Regina Santos da. O viver em

família e sua interface com a saúde e a doença. Eduem, Paraná, 2002.

FÃO, Thiago da Silva. AS DIFERENTES EXPERIÊNCIAS NA CONSTRUÇÃO DA

IDENTIDADE PROFISSIONAL. 2012. 35p. Trabalho de Conclusão de Curso

(Monografia). Orientadora Alessandra Dartora da Silva. Curso de Enfermagem. Centro

Universitário Metodista IPA, Porto Alegre.

FARIA, Lina; SANTOS, Luiz Antonio de Castro. As profissões de saúde: uma análise crítica do cuidar. História, Ciências, Saúde - Manguinhos, Rio de Janeiro, v.18, supl.1, p.227-40, dez, 2011.

FERRAZ, Fabiane et al . Cuidar-educando em enfermagem: passaporte para o aprender/educar/cuidar em saúde. Rev. bras. enferm., Brasília , v. 58, n. 5, p. 607-610, out 2005.

FILIPPON, Jonathan; KANTORSKI, Luciane Prado. Humanização e loucura, em busca do humano que dialoga saúde. Physis Rev. de Saúde Coletiva, Rio de Janeiro, v.22, n.2, p.659$80,2012$.

FRANÇOSO, L.P.C. Reflexões sobre o preparo do enfermeiro na área de oncologia pediátrica. Rev. Latino-am. Enfermagem, Ribeirão Preto, v. 4, n. 3, p. 41-48, dez 1996.

GARROS, Daniel. Uma "boa" morte em UTI pediátrica: é isso possível?. J. Pediatr. (Rio J.), Porto Alegre, v. 79, supl. 2, p. S243-S254, nov 2003.

GIL, Antonio Carlos. Como elaborar projetos de pesquisa. $4^{\text {a }}$ Ed. São Paulo: Atlas, 2002. $175 p$.

HOSTERT, Paula Coimbra da Costa Pereira; ENUMO, Sônia Regina Fiorim; LOSS,

Alessandra Brunoro Motta. Brincar e problemas de comportamento de crianças com câncer de classes hospitalares. Psicol. teor. prat., São Paulo, v. 16, n. 1, p. 127-140, abr. 2014. 
IGOR, Érick. Formação da identidade profissional de enfermagem: uma reflexão teórica.

Estud. Pesqui. Psicol. [online], v.10, n.3, p.967-971, 2010. Disponível em:

<http://www.revispsi.uerj.br/v10n3/artigos/pdf/v10n3a20.pdf>

INSTITUTO NACIONAL DE CÂNCER JOSÉ ALENCAR GOMES DA SILVA (INCA).

Tipos de Câncer Infantil. Rio de Janeiro. 2016. Disponível em

<http://www2.inca.gov.br/wps/wcm/connect/tiposdecancer/site/home/infantil > Acessado em 24 de abril de 2018.

JUNGES, José Roque et al. Reflexões legais e éticas sobre o final da vida: uma discussão sobre a ortotanásia. Revista Biomédica, v.18, n.2, p.275-88, 2010.

LEITÃO, Arlinda Martins Ribeiro; VIEIRA, Josenilton Nunes. Ser Pedagoga: Narrativas autobiográficas de uma egressa do curso de pedagogia da UNEB Campus III / Juazeiro Bahia. In: Congresso Internacional de Pesquisa (Auto)biográfica, 5, 2012, Porto Alegre. Anais. Porto Alegre: Leiria, 2012, p.96-101.

MARQUES, Ana Paula Felippe de Souza. Cancer and stress: a study on children in chemotherapy treatment. Psicol. hosp. (São Paulo), São Paulo, v. 2, n. 2, dez. 2004.

MARTINS, Alexandra da Rosa et al. Relações interpessoais, equipe de trabalho e seus reflexos na atenção básica. Rev. Brasileira de Educação Médica, Brasília, v.36, supl.2, p.6$12,2012$.

MINAYO, Maria Cecília de Souza. O desafio do conhecimento: Pesquisa qualitativa em saúde. $12^{a}$ ed. São Paulo: Hucitec, 2010, 407p.

MONTEIRO, Ana Ruth Macêdo et al. Sofrimento psíquico em crianças e adolescentes - a busca pelo tratamento. Esc. Anna Nery, Rio de Janeiro, v.16, n.3, p.523-29, jul/set, 2012.

OLIVEIRA, Denize Cristina et al. Construção de um paradigma de cuidado de enfermagem pautado nas necessidades humanas e de saúde. Esc. Anna Nery, Rio de Janeiro, v.15, n.4, p.838-44, out/dez, 2011. 
OLIVEIRA, Fernanda Maria do Carmo da Silveira Neves et al. Educação permanente e qualidade da assistência à saúde: aprendizagem significativa no trabalho da enfermagem. Aquichán [online], Colômbia, v.11, n.1, p.48-65, abr, 2011 b.

ORTIZ, Marta Cristina Meirelles. À margem do leito: a mãe e o câncer infantil. Arte \& Ciência, Espírito Santo, 2003.

PAULA, Érica Simpionato de, et al. Religião e espiritualidade: experiência de famílias de crianças com Insuficiência Renal Crônica. Revista Brasileira de Enfermagem, Brasília, v. 62, n. 1, p. 100-106, 2009.

PEDROSA, Márcia Ferreira et al . Linfoma não-Hodgkin na infância: características clínicoepidemiológicas e avaliação de sobrevida em um único centro no Nordeste do Brasil. J.

Pediatr. (Rio J.), Porto Alegre, v. 83, n. 6, p. 547-554, Dezembro. 2007.

PINAFO, Elisangela; NUNES, Elisabete de Fátima Polo de Almeida; GONZÁLEZ, Alberto Durán. A educação em saúde na relação usuário-trabalhador no cotidiano de equipes de saúde da família. Ciência e Saúde Coletiva, Rio de Janeiro, v.17, n.7, p.1825-32, 2012.

\section{POLIT, Denise F.; BECK, Cheryl Tatano. Fundamentos de Pesquisa em Enfermagem:} avaliação de evidências para a prática da enfermagem. $7^{\text {a }}$ Ed. Porto Alegre: Artmed, 2011, $669 \mathrm{p}$.

SILVA, Denise Conceição; ALVIM, Neide Aparecida Titonelli; Figueiredo, Paula Alvarenga. Tecnologias leves em saúde e sua relação com o cuidado de enfermagem hospitalar. Esc. Anna Nery, Rio de Janeiro, v.12, n.2, p.291-8, jun, 2008.

SILVA, Patricia Karla de Souza e; MELO, Symone Fernandes de. Experiência materna de perda de um filho com câncer infantil: um estudo fenomenológico. Rev. abordagem gestalt., Goiânia , v. 19, n. 2, p. 147-156, dezembro 2013. 
SPAGNOL, Carla Aparecida et al. Situações de conflito vivenciadas no contexto hospitalar: a visão dos técnicos e auxiliares de enfermagem. Revista Esc. Enferm. USP, São Paulo, v.44, n.3, p.803-11, 2010.

SPOSITO, Amanda Mota Pacciulio et al . Estratégias lúdicas de coleta de dados com crianças com câncer: revisão integrativa. Rev. Gaúcha Enferm., Porto Alegre, v. 34, n. 3, p. 187195, Sept. 2013.

TOLEDO, Andréia Padilha; PRIOLLI, Denise Gonçalves. Cuidados no fim da vida: o ensino médico no Brasil. Rev. Brasileira de Educação Médica, Brasília, v.36, n.1, p.109-17, 2012.

UMANN, Juliane; GUIDO, Laura de Azevedo; FREITAS, Etiane de Oliveira. Produção de conhecimento sobre saúde e doença na equipe de enfermagem na assistência hospitalar.

Cienc. Cuid. Saúde, Paraná, v.10, n.1, p.162-8, jan/mar, 2011.

VALLE, Elizabeth Ranier Martins do, \& FRANÇOSO, Luciana Pagano Castilho.

Psicooncologia pediátrica: Vivências de crianças com câncer. Ribeirão Preto, SP: Scala., 1999.

VIEIRA, Maria Aparecida. Doença crônica: vivências de crianças e adolescentes. Tese de Doutorado USP, São Paulo, 2001.

WALDOW, Vera Regina; BORGES, Rosália Figueiró. Cuidar e humanizar: relações e significados. Acta Paul. Enferm., São Paulo, v.24, n.3, p.414-8, 2011.

WALDOW, Vera Regina; BORGES, Rosália Figueiró. O processo de cuidar sob a perspectiva da vulnerabilidade. Rev. Latino-am. Enfermagem [online], v.16, n.4, 8p., jul/ago, 2008.

WILFRED, McSherry. The principal components model: a3 model for advancing spirituality and spiritual care within nursing and health care practice. Journal of clinical nursing, v. 15, n. 7, p. 905-917, 2006. 